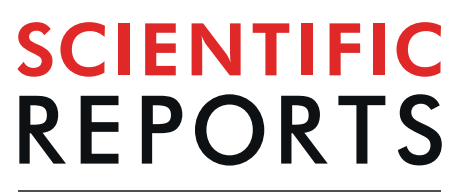

natureresearch

\title{
OPEN Ultra high-resolution seawater density sensor based on a refractive index measurement using the spectroscopic interference method
}

\begin{abstract}
Hiroshi Uchida $\mathbb{1}^{1 *}$, Yohei Kayukawa ${ }^{2}$ \& Yosaku Maeda ${ }^{3}$
The interference method is one of the most sensitive methods for measuring the refractive index of seawater. We developed a state-of-the-art density sensor for seawater measurements based on measuring the refractive index by the interference method. The resolution of the density sensor is $0.00006 \mathrm{~kg} / \mathrm{m}^{3}$ for changing temperature at constant salinity and pressure, $0.00012 \mathrm{~kg} / \mathrm{m}^{3}$ for changing salinity at constant temperature and pressure, and $0.00010 \mathrm{~kg} / \mathrm{m}^{3}$ for changing pressure at constant temperature and salinity. These resolution values are the best in the history of seawater density measurements. The ultra high-resolution density sensor will contribute notably to climate research at full ocean depth and measurement of seawater sampled from the deep ocean, to research on metrology to establish the traceability of salinity measurements, and to submarine resource exploration to detect spatial changes in the absolute salinity anomaly by combining with conventional conductance-based salinity measurements.
\end{abstract}

The Earth's climate system is driven by energy from the sun. Oceanic and atmospheric circulations transfer this energy from the low latitudes of Earth's surface to higher latitudes. The ocean's central role in the climate system results from its great capacity to store and transport heat and water and exchange these with the atmosphere. Surface water that cools around Antarctica sinks and forms bottom water, which spreads over the entire global ocean. Recent high-quality hydrographic observations have revealed bottom water warming: $2 \mathrm{mK}$ decade $^{-1}$ in the North Pacific ${ }^{1}$ and around $30 \mathrm{mK}$ decade $^{-1}$ in the Southern Ocean ${ }^{2}$. A supercomputer simulation has shown that surface warming events in the Southern Ocean may cause significant temperature changes in the North Pacific deep water ${ }^{3}$. Ocean salinity is also being recognized as an important indicator of climate change; Antarctic ice-sheet melting is freshening the bottom water around Antarctica ${ }^{4}$. At present, however, even the highest possible quality salinity measurements (uncertainty of about $0.001 \mathrm{~g} / \mathrm{kg}$ ) are not adequate for climate studies in the deep ocean, except for regions close to the sources of deep water ${ }^{5,6}$.

For example, in the western North Pacific along $149^{\circ} \mathrm{E}$, the meridional gradients of temperature and salinity in the deep ocean are about $2 \mathrm{mK}$ and $0.0002 \mathrm{~g} / \mathrm{kg}$ per $100 \mathrm{~km}$, respectively ${ }^{7}$. However, the resolutions of temperature and salinity measurements by the conductivity-temperature-depth (CTD) system (SBE 9plus, Sea-Bird Scientific, Bellevue, Washington), which is widely used for high-quality measurements ${ }^{8}$, are $0.2 \mathrm{mK}$ and $0.0004 \mathrm{~g} / \mathrm{kg}$, respectively. This means that the spatial resolution of the salinity measurement is 20 times coarser than that of the temperature measurement. In addition, ambiguity of the certified salinity value $( \pm 0.001 \mathrm{~g} / \mathrm{kg}) \mathrm{of}$ the International Association of the Physical Sciences of the Ocean (IAPSO) Standard Seawater (SSW) (Ocean Scientific International Ltd., Havant, UK) used to calibrate laboratory salinometers is also a serious problem ${ }^{9}$ that results from the lack of traceability to the International System of Units $(\mathrm{SI})^{10}$. Moreover, absolute salinity, which is needed to calculate the density of seawater from conventional conductance-based salinity measurements with a correction algorithm that uses the global atlas of silicate concentrations in the International Thermodynamic Equation of Seawater 2010 (TEOS-10) ${ }^{11}$, has problems such as the latitude-dependent error induced from the

\footnotetext{
${ }^{1}$ Research Institute for Global Change, Japan Agency for Marine-Earth Science and Technology, Yokosuka, Japan. ${ }^{2}$ National Metrology Institute of Japan, National Institute of Advanced Industrial Science and Technology, Tsukuba, Japan. ${ }^{3}$ Institute for Marine-Earth Exploration and Engineering, Japan Agency for Marine-Earth Science and Technology, Yokosuka, Japan. *email: huchida@jamstec.go.jp
} 
Measuring cell (synthetic silica glass)

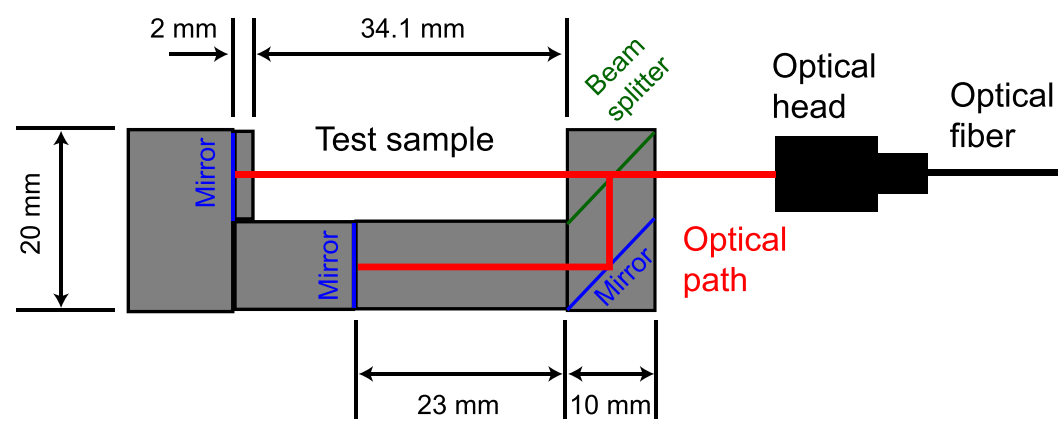

Figure 1. Schematic illustration of the density measuring cell for measurement of the refractive index difference between the test sample and synthetic silica glass. The thickness of the cell is $10 \mathrm{~mm}$. The light beam spot size is about $20 \mu \mathrm{m}$. Light from the optical head is split into two paths by a beam splitter. One path goes through the test sample and the other path goes through the glass as a reference optical path. Both light beams reflect at terminal mirrors and return via the original path. The optical head consists only of optical fibers and lenses without electronic parts, which eliminates errors due to heat generation and electromagnetic noise in the measurement.

correction algorithm ${ }^{12}$, the effect of high total alkalinity caused by river water in the Arctic Ocean ${ }^{13}$, and the time change of the magnitude of the correction due to the effect of ocean acidification ${ }^{14}$.

Interest in the refractive index-based measurement of density (or absolute salinity) has revived because it could help resolve these problems ${ }^{15}$. In fact, a double-prism V-block refractometer was tested at sea and made commercially available as an absolute salinity sensor ${ }^{16}$, although the pressure resistance $(20 \mathrm{MPa})$ and the resolution of the salinity measurement $(0.001 \mathrm{~g} / \mathrm{kg})$ are not adequate to detect decadal-time-scale salinity change in the deep ocean. Meanwhile, the interference method is known to be one of the most sensitive ways to measure the index, and it has been reported that the resolution of the salinity measurement $(0.0007 \mathrm{~g} / \mathrm{kg})$ is better than that of the V-block refractometer ${ }^{17}$, although the sensor has not yet been put to practical use. We therefore developed a practical seawater density (or absolute salinity) sensor based on high-resolution measurement of the refractive index by the spectroscopic interference method that can be used for climate studies in the laboratory and in the deep ocean.

\section{Results}

State-of-the-art density sensor. We developed a seawater density sensor by combining a density measuring cell and a commercially available thickness meter. The density-measuring cell is composed of optical components made from synthetic silicate glass (Fig. 1). The difference between the two optical path lengths $(\delta X)$ can be written as

$$
\delta X=\left(X_{s} n_{s}+X_{g 1} n_{g}-X_{g 2} n_{g}\right) / n_{a}
$$

where $X_{\mathrm{s}}(34.1 \mathrm{~mm})$ is the length of the test sample, $X_{\mathrm{g} 1}(7 \mathrm{~mm})$ is the length of the glass in the optical path for the test sample, $X_{\mathrm{g} 2}(38 \mathrm{~mm})$ is the length of the glass in the reference optical path, $n_{\mathrm{s}}$ is the refractive index of the test sample, $n_{\mathrm{g}}$ is the refractive index of the synthetic silica glass (about 1.453), and $n_{\mathrm{a}}$ is the refractive index of air at the calibration of the thickness meter (about 1.00027). We used a spectroscopic interference thickness meter (model SI-F80, Keyence Co., Osaka, Japan) to detect $\delta X$ (sensor output). The measurement principle of the thickness meter is described in Supplementary Information (see Fig. S1). Broad wavelength light (central wavelength of $0.820 \mu \mathrm{m}$ ) is emitted from a superluminescent diode. The interference light of the two reflected light beams from the measuring cell is split into different wavelengths with the spectroscope, and $\delta X$ is determined by waveform analysis (nominal range of $\delta X$ is 50 to $1100 \mu \mathrm{m}$ with a resolution of $0.001 \mu \mathrm{m})$.

Laboratory test of the density sensor. We tested the state-of-the-art density sensor (see Supplementary Information Fig. S2a) in pure water at temperatures from 1 to $30^{\circ} \mathrm{C}$ (Fig. 2a). We could easily measure $\delta X$ in the pure water mixed by stirring propellers in the temperature calibration bath. The sensor output changed depending on changes in temperature of the pure water (maximum rate of temperature change was $0.21^{\circ} \mathrm{C} \mathrm{min}{ }^{-1}$ ) (the $68 \%$ response time was shorter than $1 \mathrm{~s}$; see Supplementary Information Fig. S3). The density of the pure water was predicted from the sensor output and was compared with the density calculated from the equation of state (TEOS-10) to examine the performance of the sensor (precision, short-term stability, repeatability, and temperature hysteresis) for the pure water measurement. To predict the density $(\rho)$ from the sensor output, a multivariate (sensor output $[\delta X]$, temperature $[T]$, and pressure $[P]$ ) polynomial curve was fitted to minimize the difference between the calculated density and the predicted density by least squares fitting as follows: 

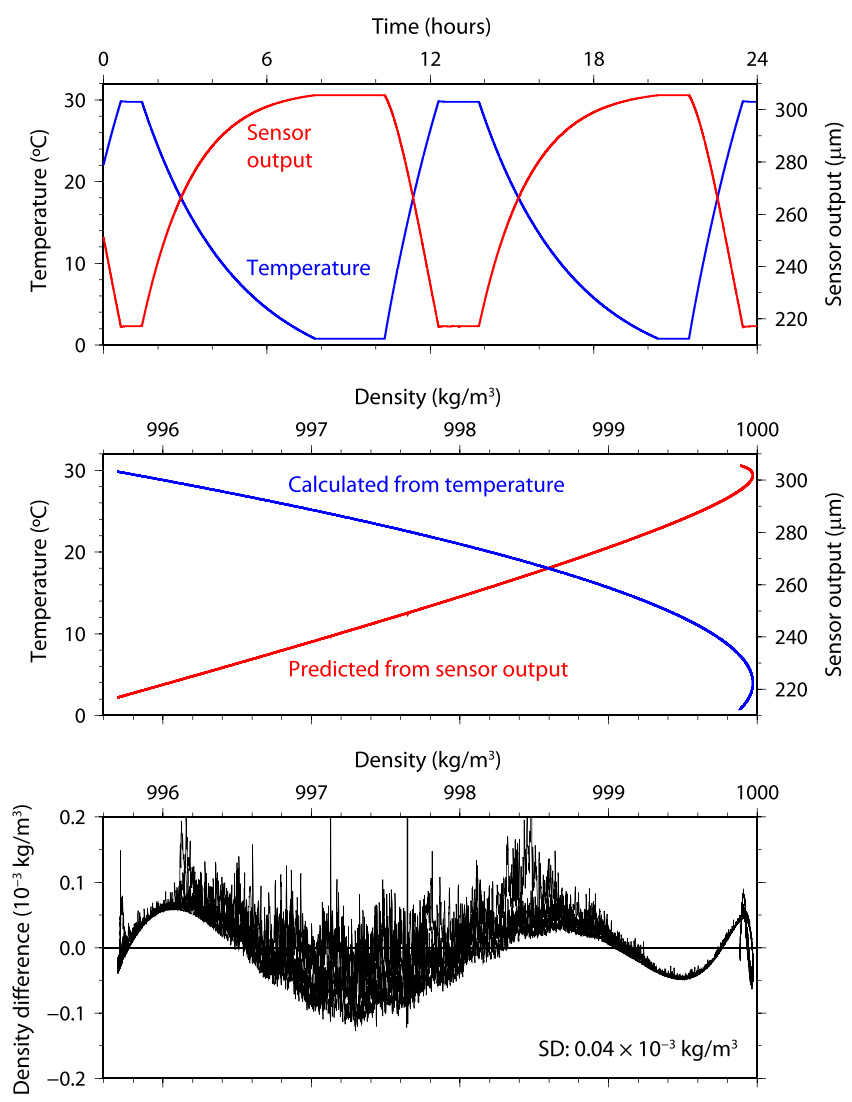

Figure 2. Pure water measurement in the temperature calibration bath. (a) Time series of temperature (blue line) of the test sample and sensor output (red line) from the density sensor under atmospheric pressure. The measuring cell (Fig. 1) of the density sensor and the reference thermometer were immersed in pure water in the temperature calibration bath. (b) Comparison of densities calculated from the equation of state (TEOS-10) with measured temperature (blue line) and predicted from the sensor output (red line) for all data (86,769 pairs) shown in (a). (c) Difference between the calculated and predicted densities. The predicted density is estimated from Eq. (2) and the fitting coefficients determined by minimizing the sum of the squares of the differences. The standard deviation of the density difference was $0.04 \times 10^{-3} \mathrm{~kg} / \mathrm{m}^{3}$.

$$
\begin{aligned}
\rho= & C_{0}+C_{1} T+C_{2} T^{2}+C_{3} T^{3}+C_{4} T^{4}+C_{5} T^{-1}+C_{6} \delta X+C_{7} \delta X^{2}+C_{8} \delta X^{3} \\
& +C_{9} \delta X T+C_{10} \delta X T^{2}+C_{11} \delta X T^{3}+C_{12} \delta X T^{4}+C_{13} \delta X T^{-1}+C_{14} \delta X^{2} T \\
& +C_{15} P+C_{16} P^{2}+C_{17} \delta X P+C_{18} \delta X T P,
\end{aligned}
$$

where $C x[x=0-18]$ are the fitting coefficients, and $P=0$ here. The predicted density derived from all the sensor outputs followed nearly the same curve (Fig. 2b). The difference between the calculated and predicted densities is shown in Fig. 2c. The precision was estimated to be $0.04 \times 10^{-3} \mathrm{~kg} / \mathrm{m}^{3}$ from the standard deviation of the density difference. The short-term stability was evaluated from the data obtained at constant temperature for $142 \mathrm{~min}$ (time from 7.92 to 10.30 hours in Fig. 2a). The means with standard deviations for the temperature and sensor output were $0.7679 \pm 0.00048^{\circ} \mathrm{C}$ and $305.563 \pm 0.0091 \mu \mathrm{m}$, respectively. In addition, the means with standard deviation for both densities calculated from the temperature and predicted from the sensor output was $999.88669 \pm 0.00003 \mathrm{~kg} / \mathrm{m}^{3}$. Since the correlation coefficient between the two densities was 0.992, most of the very small variation in the predicted density is explained by the actual density variation due to small temperature variation. Both the repeatability and temperature hysteresis were typically within $\pm 0.0001 \mathrm{~kg} / \mathrm{m}^{3}$.

Similarly, we also tested the density sensor in seawater with absolute salinity $\left(\mathrm{S}_{\mathrm{A}}\right)$ values of $7.8,17.3,26.6$, and $35.1 \mathrm{~g} / \mathrm{kg}$. The relationship between $\mathrm{S}_{\mathrm{A}}$ and the sensor output $(\delta X)$ at temperatures of $0,5,10,15,20,25$, and $30^{\circ} \mathrm{C}$ is shown in Fig. 3. As in previous studies (e.g., ref. ${ }^{18}$ ), the sensor output showed good linearity with salinity. The sensitivities to the salinity and corresponding density change were evaluated to be $6.79 \mu \mathrm{m} /(\mathrm{g} / \mathrm{kg})$ and $8.48 \mu \mathrm{m} /$ $\left(\mathrm{kg} / \mathrm{m}^{3}\right)$ from the gradients $d(\delta X) / d \mathrm{~S}_{\mathrm{A}}$ and $d(\delta X) / d \rho$, respectively, at a temperature of $0{ }^{\circ} \mathrm{C}$. Moreover, the sensitivities to the temperature and corresponding density change were evaluated to be $-3.89 \mu \mathrm{m} /{ }^{\circ} \mathrm{C}$ and $16.70 \mu \mathrm{m} /$ $\left(\mathrm{kg} / \mathrm{m}^{3}\right)$ from the gradients $d(\delta X) / d T$ and $d(\delta X) / d \rho$, respectively, at $\mathrm{S}_{\mathrm{A}}$ of $35 \mathrm{~g} / \mathrm{kg}$. Therefore, the resolutions of the salinity and density measurements can be estimated from the sensitivities and the resolution of the sensor output $(0.001 \mu \mathrm{m})$ and are listed in Table 1. 


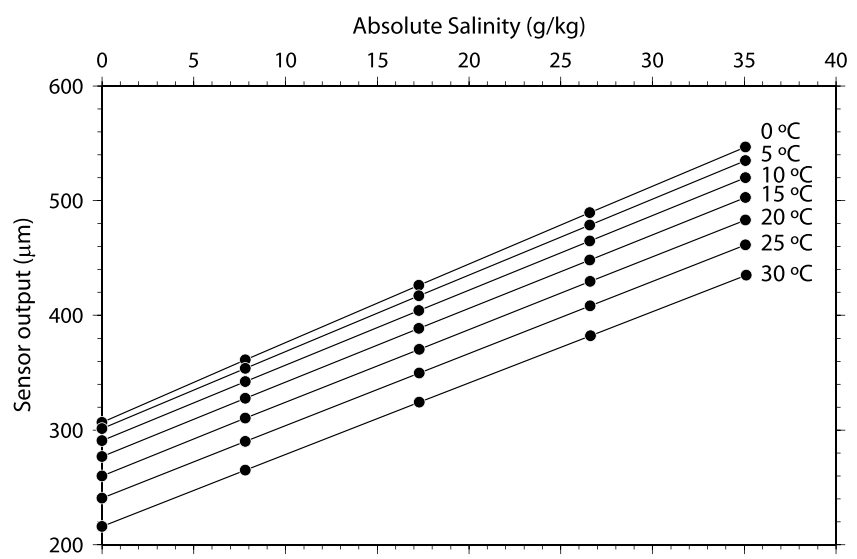

Figure 3. Sensor output plotted against absolute salinity for several temperatures of the test sample. At each salinity and temperature, the temperature and sensor output readings were averaged over $5 \mathrm{~min}$. The SDs of the temperature and sensor output were smaller than $0.3 \mathrm{mK}$ and $0.004 \mu \mathrm{m}$, respectively. The absolute salinity was estimated for each test sample at the end of each 5-min measurement by drawing the test sample for salinity analysis.

\begin{tabular}{|l|l|}
\hline Size & $\varphi 210 \mathrm{~mm} \times 500 \mathrm{~mm}$ \\
\hline Weight & $14 \mathrm{~kg}$ in air \\
\hline Depth rating & $10,500 \mathrm{~m}$ (for pressure-tight housing) \\
\hline Temperature range & Freezing point $-50^{\circ} \mathrm{C}$ (must not freeze) \\
\hline Salinity range & $0-120 \mathrm{~g} / \mathrm{kg} @$ atmospheric pressure \\
\hline Pressure range & Atmospheric pressure- $120 \mathrm{MPa}$ \\
\hline Resolution & $0.00006 \mathrm{~kg} / \mathrm{m}^{3} @ 35 \mathrm{~g} / \mathrm{kg}($ for changing temperature) \\
& $0.00012 \mathrm{~kg} / \mathrm{m}^{3}(0.00015 \mathrm{~g} / \mathrm{kg}) @ 1{ }^{\circ} \mathrm{C}$ (for changing salinity) \\
& $0.00010 \mathrm{~kg} / \mathrm{m}^{3} @ 35 \mathrm{~g} / \mathrm{kg}($ for changing pressure) \\
\hline Sampling frequency & $5000 \mathrm{~Hz}$ (for practical measurement resolution of $\left.0.01 \mathrm{~kg} / \mathrm{m}^{3}\right)$ \\
& $1.2 \mathrm{~Hz}$ (for practical measurement resolution of $\left.0.0001 \mathrm{~kg} / \mathrm{m}^{3}\right)$ \\
\hline
\end{tabular}

Table 1. Specifications of the state-of-the-art seawater density sensor. Size and weight are approximate. Temperature range was limited by the manufacturer's specifications for the spectroscopic interference thickness meter. Salinity range was estimated from the limited laboratory experiment at atmospheric pressure (Fig. 3) by extrapolating to both ends of the measurement range $(50-1100 \mu \mathrm{m})$ of the thickness meter. Pressure range was estimated from the limited field experiment (Fig. 4) by extrapolating to both ends of the measurement range of the thickness meter. The resolution was estimated from the sensitivity to salinity change $(6.79 \mu \mathrm{m} /[\mathrm{g} / \mathrm{kg}])$ and corresponding density change $\left(8.48 \mu \mathrm{m} /\left[\mathrm{kg} / \mathrm{m}^{3}\right]\right)$ at constant temperature and pressure, and changing temperature $\left(-3.89 \mu \mathrm{m} /{ }^{\circ} \mathrm{C}\right)$ at constant salinity and pressure estimated from the laboratory experiment and the resolution of the sensor output $(0.001 \mu \mathrm{m})$. The resolution for changing pressure was also estimated from the sensitivity to pressure change $(4.4 \mu \mathrm{m} / \mathrm{MPa})$ at nearly constant temperature and salinity (deep ocean). To achieve finest measurement resolution of $0.001 \mu \mathrm{m}$, the sensor output will have to be averaged over $0.82 \mathrm{~s}$ (4096 data points).

Field test of the density sensor. We tested the density sensor in the North Pacific (up to $60 \mathrm{MPa}$ ) with the CTD/water sampling system of the RV Mirai in May 2019 (see Supplementary Information Fig. S2b). The sensor output changed depending on changes in pressure similarly to the in situ density calculated from the equation of state (TEOS-10) (Fig. 4a). To predict the in situ density from the sensor output, a multivariate polynomial curve (Eq. 2) was used to minimize the difference between the calculated density and the predicted density by least squares fitting (Fig. 4b). The difference between the calculated and predicted densities is shown in Fig. 4c. The standard deviations of the density differences were determined to be 0.0004 and $0.0038 \mathrm{~kg} / \mathrm{m}^{3}$ for pressures greater than and smaller than $20 \mathrm{MPa}$, respectively. To the best of the authors' knowledge, this was the first refractive index-based measurement of in situ seawater density in the deep ocean (pressure greater than $20 \mathrm{MPa}$ ).

\section{Discussion}

Determination of the density from the density sensor. In principle, the refractive index of the test sample can be determined from Eq. (1). In practice, however, it is not easy to precisely quantify the refractive index of the glass and the lengths of the glass and test sample. Therefore, it is practical to directly estimate the density of the test sample from the sensor output. The empirical equation to predict the density should be a function of the sensor output, temperature, and pressure.

Next, we tried to estimate the density from the sensor output by using the results of the laboratory test of pure water and seawater measurements (Fig. 3). The multivariate (sensor output, temperature, and pressure) 


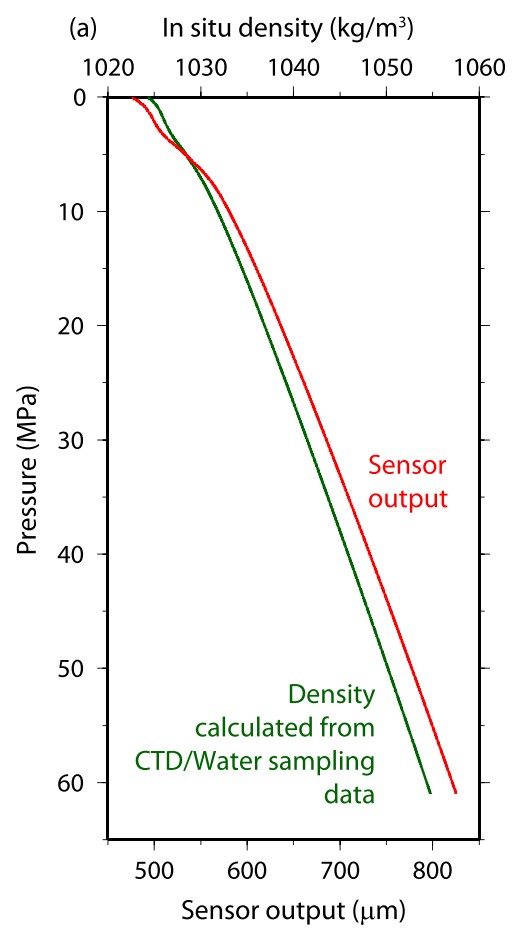

(b) In situ density $\left(\mathrm{kg} / \mathrm{m}^{3}\right)$
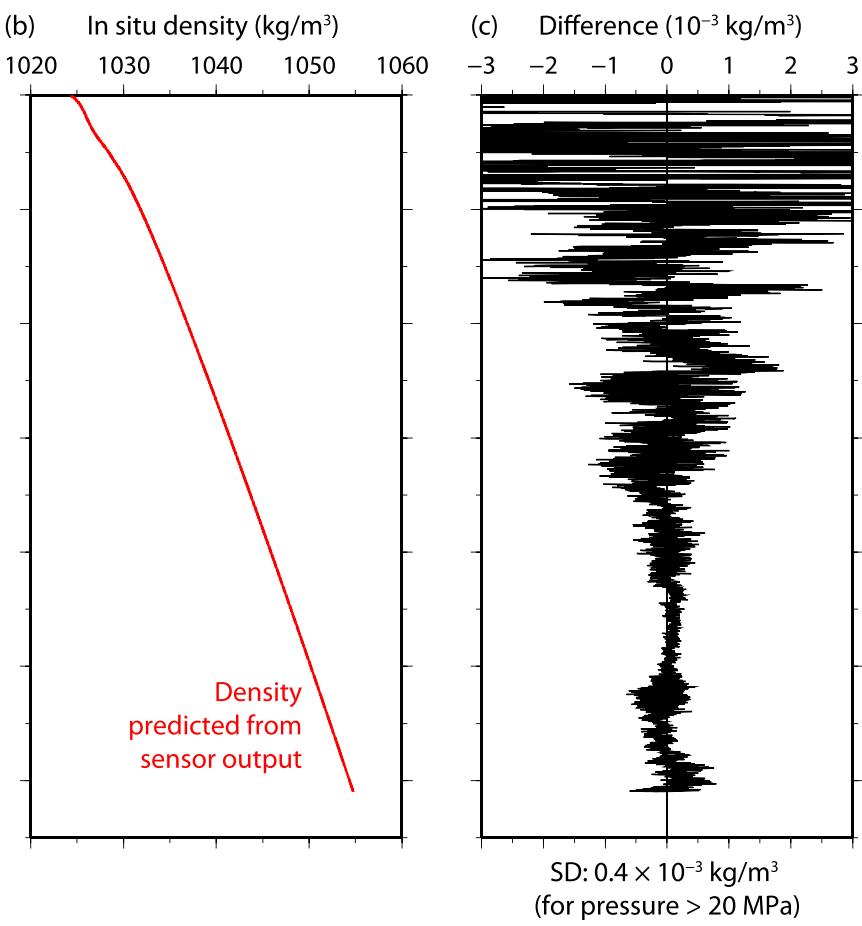

Figure 4. Seawater measurement in the deep ocean of the North Pacific $\left(32.2^{\circ} \mathrm{N}, 144.3^{\circ} \mathrm{E}\right)$. (a) Vertical profiles of in situ density (green line) calculated from CTD/water sampling data and output (red line) from the density sensor. (b) Vertical profile of in situ density predicted from the density sensor output. (c) Difference between the calculated and predicted densities. The predicted density is estimated from Eq. (2), and the fitting coefficients determined by minimizing the sum of the squares of the differences. The standard deviation of the density difference was $0.4 \times 10^{-3} \mathrm{~kg} / \mathrm{m}^{3}$ for pressure greater than $20 \mathrm{MPa}$.

polynomial curve (Eq. 2) was fitted to the sensor output by the least squares method. The standard deviation of the density difference between the calculated and predicted densities was larger $\left(0.0011 \mathrm{~kg} / \mathrm{m}^{3}\right)$ than the result for only pure water $\left(0.00004 \mathrm{~kg} / \mathrm{m}^{3}\right.$, Fig. $\left.2 \mathrm{c}\right)$. Although the residual may be smaller than the value in a previous study $\left(0.0035 \mathrm{~kg} / \mathrm{m}^{3}\right)^{19}$, it still must be reduced. Possible sources of this large residual are (1) insufficient empirical function used to predict the density, (2) error caused by nonlinearity of the spectroscopic interference thickness meter, and (3) error in the equation of state of seawater (TEOS-10). The second possible source seems likely because similar undulations of the density difference were seen in the laboratory and in the deep ocean (Figs $2 \mathrm{c}$ and $4 \mathrm{c}$ ), although such undulations were not present in one portion of Fig. 4c (e.g., pressure from 42.5 to $50 \mathrm{MPa}$ or sensor output from 744 to $777 \mu \mathrm{m}$ ). These undulations might be caused by a nonlinearity of the thickness meter. The third possible source would be a serious problem and is discussed below.

When using the density sensor in the laboratory at constant temperature and pressure (atmospheric pressure), the calibration equation can be expressed as a function of only the sensor output. Because the sensor output shows good linearity with salinity (Fig. 3), the density sensor could be more precisely calibrated than the in situ sensor. In other words, the salinity of seawater sampled from the deep ocean could be measured more precisely in the laboratory than in the deep ocean for climate studies free from the effects of temperature and pressure changes.

Density error of TEOS-10. Uncertainty in the density dataset for standard seawater used in TEOS-10 is estimated to be $0.004 \mathrm{~kg} / \mathrm{m}^{3}$ at atmospheric pressure for salinities up to $42 \mathrm{~g} / \mathrm{kg}$ and for temperatures up to $40^{\circ} \mathrm{C}^{20}$. In addition, a recent density measurement of standard seawater by means of a vibrating-tube density meter suggests that the density calculated from TEOS-10 increasingly deviates with salinity, with the increase approximately linear and about $0.015 \mathrm{~kg} / \mathrm{m}^{3}$ at salinity of $35 \mathrm{~g} / \mathrm{kg}^{21}$. This result is supported by their density measurement by means of hydrostatic weighing ${ }^{22}$. However, another study reported a smaller density deviation $\left(0.0064 \mathrm{~kg} / \mathrm{m}^{3}\right)$ based on a vibrating-tube density meter ${ }^{12}$, and our recent results of density measurements by means of hydrostatic weighing showed almost no deviation. A way to resolve this discrepancy would be to evaluate the density of standard seawater as accurately as possible by means of hydrostatic weighing as the primary standard method, preferably by multiple institutions.

In situ density sensor. Typically, turbidity and sunlight can affect optical measurements of the density sensor in the surface ocean $(\sim 100 \mathrm{~m})$, although optical measurements in the deep ocean are free from these effects. Density non-uniformity in a test sample along the optical path $(34.1 \mathrm{~mm})$ of the measuring cell may occur due to oceanic temperature and salinity microstructures. However, the density sensor measures the average of the refractive index of the test sample along the optical path. In addition, the effect of temperature and salinity 
microstructures might be removed by averaging the obtained data in time and space, similar to a standard CTD observation (e.g., temperature and salinity vertical profiles are usually averaged at an interval of 1 or 2 dbar in climate studies).

The sensitivity to pressure change $(4.4 \mu \mathrm{m} / \mathrm{MPa})$ in the deep ocean (Fig. 4$)$ is mainly due to the in situ density change and therefore change of $n_{\mathrm{s}}$ in Eq. (1), but it may also be due to pressure dependency of the measurement cell (a change of geometry $\left[X_{\mathrm{s}}, X_{\mathrm{g} 1}\right.$ and $X_{\mathrm{g} 2}$ in Eq. 1] and a change of refractive index of the synthetic silica glass [ $n_{\mathrm{g}}$ in Eq. 1]). It is difficult to separate these effects from the sensor output. Therefore, we empirically predicted the density from the sensor output by the polynomial curve (Eq. 2).

We will also test the density sensor in the Izu-Ogasawara Trench $(\sim 9300 \mathrm{~m})$ with the CTD/water sampling system of the RV Kaimei $i^{23}$. The hadal zone (depths greater than around $6000 \mathrm{~m}$ ) in ocean trenches is one of the last frontiers in the global ocean ${ }^{24}$. Density measurements in situ and for water samples in the trench should be suitable for more precise evaluation of the pressure dependency of the density sensor because potential density profiles obtained in the trench are reasonably homogeneous ${ }^{23}$.

Comparison with the de facto standards. We compared the density measurement resolution of the state-of-the-art density sensor with those of the de facto standard salinometer, densimeter, and refractometer. The resolution of the laboratory conductivity salinometer (Autosal 8400B, Guildline Instruments Ltd., Ontario, Canada) is $0.00015 \mathrm{~kg} / \mathrm{m}^{3}(0.0002 \mathrm{~g} / \mathrm{kg}$ in salinity in the range of $0.005-42 \mathrm{~g} / \mathrm{kg})$. The resolution of the in situ conductivity sensor (SBE 4, Sea-Bird Scientific) used in the SBE 9plus CTD system is $0.00030 \mathrm{~kg} / \mathrm{m}^{3}(0.0004 \mathrm{~g} / \mathrm{kg}$ in salinity). The resolution of the laboratory densimeter (DMA $5000 \mathrm{M}$, Anton-Paar GmbH, Graz, Austria) is $0.001 \mathrm{~kg} / \mathrm{m}^{3}$. The resolution of the brand-new and commercially available refractometer (NOSS sensor, nke Instrumentation, Hennebont, France $)$ is $0.0008 \mathrm{~kg} / \mathrm{m}^{3}(0.001 \mathrm{~g} / \mathrm{kg} \text { in salinity in the range of } 15-42 \mathrm{~g} / \mathrm{kg})^{25}$. To our knowledge, the resolution of the density sensor developed in this study $\left(0.00012 \mathrm{~kg} / \mathrm{m}^{3}\right.$, Table 1$)$ is the best in the history of seawater density measurements.

Future view. The state-of-the-art density sensor can measure seawater density with better resolution than the de facto standard in situ and laboratory conductivity salinometers and one order of magnitude finer than the de facto standard laboratory densimeter and in situ refractometer over a wider range of salinity $(0-120 \mathrm{~g} / \mathrm{kg})$ (see Supplementary Information Fig. S5). It is an important milestone to substitute the method of salinity measurement in the ocean from one that is conductance-based and has been used for more than 40 years to the index-based method, which can directly estimate seawater density.

We will be able to use the ultra high-resolution density sensor in research on, for example, global climate change to detect deep ocean freshening associated with global warming and Antarctic ice-sheet melting, metrology to establish the traceability of the salinity of IAPSO SSW to SI units with small uncertainty, and submarine resource exploration to detect spatial changes in the absolute salinity anomaly associated with submarine springs in real time by combining the density sensor with a conventional conductivity sensor.

\section{Methods}

Laboratory test. We measured test samples (pure water and seawater) by using the state-of-the-art density sensor under atmospheric pressure. The density-measuring cell and a reference thermometer (model SBE 35, Sea-Bird Scientific) were immersed in a refrigerated temperature calibration bath (model 7011, Fluke Co., Everett, Washington). The temperature of the test sample (about $27 \mathrm{~L}$ ) near the measuring cell was measured by the reference thermometer at a sampling interval of about $3.6 \mathrm{~s}$ and interpolated at an interval of $1 \mathrm{~s}$. The expanded uncertainty of the temperature measurement can be estimated to be $0.4 \mathrm{mK}^{26}$. The difference between the two optical path lengths $(\delta X)$ was measured at a sampling interval of $0.0002 \mathrm{~s}$ and was low-passfiltered with a half power gain at $10 \mathrm{~s}$, and the sensor output was stored at an interval of $1 \mathrm{~s}$ and merged with the temperature data. The spectroscopic unit of the thickness meter was kept at room temperature (around $23^{\circ} \mathrm{C}$ ) or put into an incubator to maintain the temperature of the unit at about $24^{\circ} \mathrm{C}$. The room temperature and temperature in the incubator were measured by a laboratory thermometer (model $1502 \mathrm{~A}$, Fluke Co.) at an interval of $1 \mathrm{~s}$ to correct for temperature dependency of the spectroscopic unit. The density error corresponding to the temperature dependency was estimated to be $0.0015\left[\mathrm{~kg} / \mathrm{m}^{3}\right] /{ }^{\circ} \mathrm{C}$ (see Supplementary Information Fig. S4).

We used ultra-pure water prepared from Yokosuka, Japan, tap water by using an ultra purification water system (model UL-Pure KE0196, Komatsu Electronics Co., Ltd., Komatsu, Ishikawa, Japan), and pure water (Pure Water [water hardness 0], Ako Kasei Co., Ltd., Ako, Hyogo, Japan) made from seawater collected from a depth of $344 \mathrm{~m}$ off Muroto, Kochi, Japan, by filtering twice with a reverse osmosis membrane. In addition, Pure Water was deionized using ion exchange resin (Pure Maker, Sanei Corp., Arao, Kumamoto, Japan). We also used Atlantic Seawater (Ocean Scientific International Ltd.) and Atlantic Seawater diluted with Pure Water. The Atlantic Seawater is the source seawater of IAPSO SSW. These test samples were installed in the temperature calibration bath and measured with the density sensor.

We calculated the densities of the test samples by using TEOS-10. For ultra-pure water, the effect of the isotopic composition ${ }^{27}$ for hydrogen $(\delta D)$ and oxygen $\left(\delta^{18} O\right)$ relative to Vienna Standard Mean Ocean Water (VSMOW) was corrected by using typical values for Yokosuka tap water $\left(\delta D\right.$ of $-59 \%$ and $\delta^{18} \mathrm{O}$ of $-9 \%$, e.g., ref. $^{12}$ ) (Fig. 2). For the Pure Water, the effect of the isotopic composition was corrected by using measured values $\left(\delta D\right.$ of $-3.4 \%$ and $\delta^{18} \mathrm{O}$ of $-1.3 \%$ ) (Fig. 3 ). The practical salinity measured for the ultra-pure water and Pure Water was 0.0000 and 0.0003 , respectively, although these values were outside the warranty range $(0.005-42$ in practical salinity) of the salinometer (Autosal $8400 \mathrm{~B}$ ). The absolute salinity was estimated for each seawater sample and temperature by drawing the seawater sample into a $100 \mathrm{~mL}$ bottle for practical salinity analysis. The 
practical salinity was measured with a salinometer (Autosal 8400B), which was standardized with IAPSO SSW batch P160. The absolute salinity anomaly was assumed to be zero for the seawater sample.

Field test. To be able to use the density sensor at full ocean depth, the spectroscopic and control units (about $130 \mathrm{~mm}$ high, $130 \mathrm{~mm}$ wide, and $130 \mathrm{~mm}$ long) are put inside a cylindrical pressure-tight housing using a ceramic cylinder (A479, Kyocera Co., Fushimi, Kyoto, Japan) and aluminum alloy (A7075-T6) hemispherical caps ${ }^{28}$ to reduce weight and cost compared to a titanium alloy housing (see Supplementary Information Fig. S2b). The specifications of the density sensor as designed and as evaluated from the laboratory and field tests are summarized in Table 1. The temperature in the pressure-tight housing was measured by a temperature logger (model Duet T.D. deep, RBR Ltd., Ottawa, Canada) at an interval of $1 \mathrm{~s}$ to correct for the temperature dependency of the spectroscopic unit. The density sensor output was low-pass-filtered with a half power gain at $1 \mathrm{~s}$, and was stored at an interval of 0.0217 s through the Serial Data Uplink of the CTD/water sampling system (SBE 9plus, Sea-Bird Scientific).

The density sensor was used with the CTD/water sampling system. The CTD data obtained at an interval of $0.0417 \mathrm{~s}$ were averaged at an interval of $1 \mathrm{~s}$. The CTD thermometer was calibrated with the reference thermometer $(\mathrm{SBE} 35)^{26}$, and the CTD salinity data were corrected by using salinity data measured for the in situ water sample data. Salinity measurements for the water samples were conducted with a salinometer (Autosal 8400B). The absolute salinity anomaly profile was estimated from the discrete water sample data (silicate, nitrate, total alkalinity, and dissolved inorganic carbon $)^{29}$ by using an Akima spline interpolation. We calculated the reference densities from the CTD and absolute salinity anomaly data by using TEOS-10. The reference density data were merged with the density sensor output and averaged at an interval of $1 \mathrm{~s}$. Down-cast profiles were used for the analysis.

Received: 5 February 2019; Accepted: 13 October 2019;

Published online: 29 October 2019

\section{References}

1. Fukasawa, M. et al. Bottom water warming in the North Pacific Ocean. Nature 427, 825-827 (2004).

2. Rhein, M. et al. Observations: Ocean. Climate Change 2013: The Physical Science Basis, Stocker, T. F. et al. Eds, Cambridge University Press, 255-315 (2013).

3. Masuda, S. et al. Simulated rapid warming of abyssal North Pacific. Science 329, 319-322 (2010).

4. Bindoff, N. L. \& Hobbs, W. R. Deep ocean freshening. Nature Climate Change 3, 864-865 (2013).

5. Purkey, S. G. \& Johnson, G. C. Antarctic Bottom Water warming and freshening: contributions to sea level rise, ocean freshwater budgets, and global heat gain. J. Climate 26, 6105-6122 (2013).

6. Dickson, B. et al. Rapid freshening of the deep North Atlantic Ocean over the past four decades. Nature 416, 832-837 (2002).

7. Uchida, H. et al. Eds., WHP P10 Revisit in 2011 Data Book, JAMSTEC, Yokosuka, Kanagawa, Japan, 179 pp., https://doi. org/10.17596/0000031 (2014)

8. Swift, J. H. Reference-quality water sample data: Notes on acquisition, record keeping, and evaluation. GO-SHIP repeat hydrography manual: A collection of expert reports and guidelines, Hood, E. M., Sabine, C. L. \& Sloyan, B. M. Eds Version 1, IOCCP Rep. 14, ICPO Publ. Series 134, 38 pp. Available online at http://www.go-ship.org/Manual/Swift_DataEval.pdf (2010).

9. Kawano, T. et al. The latest batch-to-batch difference table of standard seawater and its application to the WOCE onetime sections. J. Oceanogr. 62, 777-792 (2006).

10. Pawlowicz, R. et al. Metrological challenges for measurements of key climatological observables Part 2: Oceanic salinity. Metrologia 53, R12-R25 (2016).

11. IOC et al. The international thermodynamic equation of seawater - 2010: Calculation and use of thermodynamic properties. Intergovernmental Oceanographic Commission, Manuals and Guides No. 56, United Nations Educational, Scientific and Cultural Organization (English), 196 pp. (2010).

12. Uchida, H. et al. Absolute salinity measurements of standard seawaters for conductivity and nutrients. La mer 49, 119-126 (2011).

13. Millero, F. et al. Effect of dissolved organic carbon and alkalinity on the density of Arctic Ocean waters. Aquat. Geochem. 17, 311-326 (2011).

14. Woosley, R. J. et al. Estimating absolute salinity $\left(\mathrm{S}_{\mathrm{A}}\right)$ in the world's oceans using density and composition. Deep-Sea Res. I 93, 14-20 (2014).

15. Le Menn, M. Instrumentation and metrology in oceanography, ISTE Ltd, London, UK, 393 pp., ISBN 978-1-84821-379-1 (2012).

16. Le Menn, M. et al. Advances in measuring ocean salinity with an optical sensor. Meas. Sci. Technol. 22, 1-8 (2011).

17. Seaver, G. et al. Laboratory calibration in distilled water and seawater of an oceanographic multichannel interferometerrefractometer. J. Atmos. Oceanic Technol. 14, 267-277 (1997).

18. Malardé, D. et al. High-resolution and compact refractometer for salinity measurements. Meas. Sci. Technol. 20(015204), 8 (2009).

19. Millard, R. C. \& Seaver, G. An index of refraction algorithm for seawater over temperature, pressure, salinity, density, and wavelength. Deep-Sea Res. 37, 1909-1926 (1990).

20. Feistel, R. A Gibbs function for seawater thermodynamics for -6 to $80{ }^{\circ} \mathrm{C}$ and salinity up to $120 \mathrm{~g} \mathrm{~kg}^{-1}$. Deep-Sea Res. I 55, 1639-1671 (2008).

21. Schmidt, H. et al. The density-salinity relation of standard seawater. Ocean Sci. 14, 15-40 (2018).

22. Schmidt, H. et al. A method to measure the density of seawater accurately to the level of $10^{-6}$. Metrologia 53, 770-786 (2016).

23. Kawagucci, S. et al. Hadal water biogeochemistry over the Izu-Ogasawara Trench observed with a full-depth CTD-CMS. Ocean Sci. 14, 575-588 (2018).

24. Levin, L. et al. Global observational needs in the deep ocean. Frontiers in Marine Science. https://doi.org/10.3389/fmars.2019.00241 (2019).

25. Grosso, P. et al. Practical versus absolute salinity measurements: New advances in high performance seawater salinity sensors. DeepSea Res. I 57, 151-156 (2010).

26. Uchida, H. et al. Deep ocean temperature measurement with un uncertainty of $0.7 \mathrm{mK}$. J. Atmos. Oceanic Technol. 32, 2199-2210 (2015).

27. Menaché, M. \& Girard, G. Concerning the different tables of the thermal expansion of water between 0 and $40{ }^{\circ} \mathrm{C}$. Metrologia 9 , 62-68 (1973).

28. Maeda, Y. \& Asakawa, K. Development of 6,000 m class cylindrical pressure-tight housing using ceramic cylinders and metal caps. 2017 IEEE Underwater Technology (UT), https://doi.org/10.1109/UT.2017.7890323 (2017).

29. Pawlowicz, R. et al. The effects of biogeochemical processes on oceanic conductivity/salinity/density relationships and the characterization of real seawater. Ocean Sci. 7, 363-387, https://doi.org/10.5194/os-7-363-2011 (2011). 


\title{
Acknowledgements
}

This work was supported by JSPS KAKENHI Grant Numbers 26610154 and 18K03752, and JAMSTEC Specially Promoted Program 2018. It contributes to the tasks of the Joint SCOR/IAPSO/IAPWS Committee on the Properties of Seawater (JCS). H.U. thanks Toa Optical Technologies, Ltd., for making prototypes of the density measuring cells. H.U. also thanks Fumiko Nakagawa (Nagoya University) for measuring the isotopic composition of the purified water from seawater.

\section{Author contributions}

H.U. and Y.K. developed the density sensor and H.U. carried out the experiments. Y.K. developed the hydrostatic weighing apparatus for seawater measurements and conducted absolute measurements of seawater density. Y.M. designed the pressure-tight housing for the sensor used at full-ocean depth and assembled the sensor parts.

\section{Competing interests}

The authors declare no competing interests.

\section{Additional information}

Supplementary information is available for this paper at https://doi.org/10.1038/s41598-019-52020-z.

Correspondence and requests for materials should be addressed to H.U.

Reprints and permissions information is available at www.nature.com/reprints.

Publisher's note Springer Nature remains neutral with regard to jurisdictional claims in published maps and institutional affiliations.

\begin{abstract}
(c) (i) Open Access This article is licensed under a Creative Commons Attribution 4.0 International License, which permits use, sharing, adaptation, distribution and reproduction in any medium or format, as long as you give appropriate credit to the original author(s) and the source, provide a link to the Creative Commons license, and indicate if changes were made. The images or other third party material in this article are included in the article's Creative Commons license, unless indicated otherwise in a credit line to the material. If material is not included in the article's Creative Commons license and your intended use is not permitted by statutory regulation or exceeds the permitted use, you will need to obtain permission directly from the copyright holder. To view a copy of this license, visit http://creativecommons.org/licenses/by/4.0/.
\end{abstract}

(C) The Author(s) 2019 